\title{
Relation of health status with distress and job-related risk factors
}

\author{
LOLITA RAPOLIENE் $\dot{1}^{1,3, A-G}$, LINA GEDRIME் 2, 3, A-F , DAIVA MOCKEVIČIENE் 3, F, \\ ARTŪRAS RAZBADAUSKAS 3 , D
}

${ }^{1}$ Klaipeda Seamen's Health Care Centre, Klaipèda, Lithuania

${ }^{2}$ Republic Klaipeda Hospital, Klaipèda, Lithuania

${ }^{3}$ Klaipeda University, Klaipeda, Lithuania

A - Study Design, B - Data Collection, C - Statistical Analysis, D - Data Interpretation, E - Manuscript Preparation, F - Literature Search, G - Funds Collection

Summary Background. Suboptimal health status (SHS) is recognised as a subclinical, reversible stage of a chronic disease. Previous studies have proposed that SHS may be related to poor lifestyle factors, as well as work-related and study-related stress.

Objectives. The present study was designed to assess the relationship between health status, general distress and job-related risk factors.

Material and methods. A community-based, cross-sectional study was conducted in a sample of 606 current workers in Klaipeda, Lithuania, who had no history of clinically diagnosed disease. The SHS score was derived from SHSQ-25; the General Symptom Distress Scale (GSDS) was used for distress evaluation.

Results. 90\% (547) of respondents revealed an optimal health level. The main domains of SHS status were fatigue and mental status. SHS was related to cardiovascular, digestive and musculoskeletal symptoms, as well as to frequent infections and allergy. SHS was more prevalent in women. The overall health status depends on the following job-related risk factors: the professional potential to grow, rest, deadlines, competition, work experience, income, etc.

Conclusions. Health status was related to distress and mainly manifested itself through fatigue, anxiety and sleep disturbances. Resting hours, professional potential to grow, risk in another person's life and work in public have a significant influence on SHS.

Key words: health status, risk factors, workload.

Rapolienè L, Gedrimè L, Mockevičienė D, Razbadauskas A. Relation of health status with distress and job-related risk factors. Fam Med Prim Care Rev 2019; 21(2): 130-137, doi: https://doi.org/10.5114/fmpcr.2019.84549.

\section{Background}

In 1948, the WHO defined health as "a state of complete physical, mental and social well-being, and not merely the absence of disease". By another definition, health is the level of functional or metabolic efficiency of a living life. In human beings, it indicates the general condition of a people's mind, body and spirit, usually meaning to be free from illness, stress, injury or pain [1, 2]. Disease and health are among the most basic concepts in modern health care. Rather than a binary distinction between health and illness, W. Yuxue proposes a dynamic transformational model; the intermediate condition between health and illness that people pass through when they are becoming ill or regaining their health constitutes the grey zone of subhealth $[1,3,4]$. Prevention and intervention strategies aimed at SHS are similar to the concept of preventive, predictive and personalised medicine, which is an effective approach to the improvement of health, the prevention of disease and the treatment of early-stage illness [2,3]. The importance of timely prevention and early detection of disorders is increasing, as the global burden of disease is large. The overall total burden of disease rates, measured as the number of Disability Adjusted Life Years (DALYs), lost per 100000 individuals across the world, varies from 40000 to 70000 DALYs per 100000 individuals across high-burden countries, particularly in Sub-Saharan Africa [5]. The 2030 Agenda for Sustainable Development frames health and well-being as both the outcomes and foundations of social inclusion, poverty reduction and environmental protection. From a health perspective, development can be said to be "sustainable" when resources - natural and manufactured - are managed by and for all individuals in ways which support the health and well-being of present and future generations [6].

Determinants of health are the factors that influence how likely we are to stay healthy or to become ill or injured. There are three key determinants of health: social determinants, biomedical risk factors and behavioural risk factors. Social determinants are found in our everyday living and working conditions: these are the circumstances in which we grow, live, work and age. They include factors such as income, education, employment and social support $[7,8]$. A person's health is also influenced by the biomedical factors and health behaviours that are part of person's individual lifestyle and genetic make-up. Behavioural risk factors such as tobacco smoking, risky alcohol consumption, using illicit drugs, not getting enough exercise and poor eating patterns can also have a detrimental effect on health and are associated with 10 major causes of death $[7,9]$.

Previous studies have proposed that SHS may be related to poor lifestyle factors, such as going to bed late, work-related and study-related stress, physical inactivity and poor diet [2, 10-13].

Long-term activation of the stress-response system can disrupt almost all of the body's processes and increase the risk of public health issue from both health and cost perspectives; stress could enhance the risk of illness of the cardiovascular, gastrointestinal, immune and neurologic systems, as well as lead to depression and sleep disorders $[14,16]$. 
Occupational stress with physiological and emotional responses is a major hazard for many workers; it occurs when workers perceive an imbalance between their work demands and their capability and/or resources to meet their demands. Employees are becoming more frequently exposed to stressful situations, such as overwork, competition and perceived isolation [15]. The studies of the American Psychological Association show that the labour force is now more stressed than at any time in the previous decade; continuous psychosocial stress seems to be a part of the everyday reality, especially for white-collar workers [16]. The CareerCast.com Jobs Rated Job Stress report endeavours to present the best baseline understanding of workplace stress, applying 11 factors: travel, career growth potential, physical demands, environmental conditions, hazards encountered, meeting the public, competition, risk of death or grievous injury, immediate risk of another's life, deadlines, working in the public eye [17].

What are the ways to determine the difference between good health and the beginning of disease? Usually, the limits between good health and the beginning of disease are not vivid. If there was a possibility to determine this critically vital step from good health and the beginning of disease, and also to take measures, the disease possibly might not develop. However, "health" is a broad concept and is difficult to capture with any single measure. Health status is mostly measured by using pathological and clinical measures and is usually observed by clinicians or measured using instruments. It can include the measurement of signs (temperature, $\mathrm{X}$-ray, blood pressure or heart/breathing rate), symptoms according to diseases-specific checklists or suspected complications, co-morbidity, undergoing medical treatment and others. Numerous generic, disease-specific and preference-based measures also now exist that tap into the diverse aspects of functioning, well-being, symptom states and subjective perceptions of health. Generic measures tap into the broad spectrum of health concepts and are intended to be appropriate for groups differing in disease, severity and comorbidity. Disease-specific tools are designed to be applicable to specific patient populations, usually defined by disease pathology, and are likely to be sensitive to treatment and natural history. Preference-based measures are weighted assessments of health state values with life years, which yield a single aggregate score [18]. A number of SHS questionnaires have been established and evaluated in China, such as SHMS V1.0, Suboptimal Health Status Questionnaire (SHSQ-25) and Multidimensional Sub-health Questionnaire of Adolescents (MSQA).

\section{Objectives}

The aim of the present study was to evaluate workers' health status and to verify its relation with general distress, as well as job-related factors.

\section{Material and methods}

A community-based, cross-sectional study was conducted in the period of February and March in 2018 in Klaipeda, Lithuania. A questionnaire-based survey was carried out with the authorisation of Kaunas Regional Biomedical Research Ethics Committee (permission No. BE-2-1). During the 2-month study period, a total of 1000 questionnaires were distributed in Klaipeda Seamen's Health Care Centre Prevention department, and an online survey was sent to the personnel department of different types of workplaces. The sample size was calculated by an online survey system sample size calculator according to number of current workers in Klaipeda city, with a 95\% confidence level and confidence interval of 3 . Inclusion criteria were as follows: $18-65$ years of age, currently working, no history of clinically diagnosed disease, willingness and possibility to partic- ipate in a continuous experimental study. The study outcomes: prevalence of suboptimal health, size and expression of general distress and their relations to each other including job-related factors.

The questionnaire was composed of socio-demographic, job-related and lifestyle-related questions, as well as 2 scales (health status and general distress scale). The SHS score was derived from the data collected in the SHSQ-25. The SHSQ-25 includes 25 items on SHS and is targeted at physiological and psychological SHS; it is a reliable and valid instrument for measuring sub-health status [16]. The range of the score of the SHSQ-25 is from 0 to 100 points. 0 points indicate the lowest level (good health) and 100 points indicate the highest level of health (poor health). Suboptimal health status is defined as an SHSQ-25 score above 35 points. The higher the score of the SHSQ-25 one gets, the more severe his or her suboptimal health status is. The SHSQ-25 highlights the multidimensionality of SHS by encompassing the following domains: (1) fatigue, (2) cardiovascular system, (3) digestive tract, (4) immune system and (5) mental status. The SHSQ-25 is short and easy to complete and, therefore, is an instrument suitable for use in both large-scale studies of the general population and a routine health survey. The General Symptom Distress Scale (GSDS) was used for measuring distress [19] and was chosen due to its adequate internal consistency, reliability, good constructional and prognostic validity, good correlation with depression and positive and negative affects [17]. This short psychometric study allows one to assess specific symptoms, rating them against each other, evaluating their strength and control of the situation. The Visual Analogue Scale (VAS) - a psychometric response scale - was used to measure the intensity and management of distress symptoms as part of GSDS.

Data is reported as the mean \pm SD for continuous variables, or as frequencies in the case of categorical variables. Descriptive statistics and univariate analyses were carried out using SPSS V23.0 (SPSS Inc, Chicago, Illinois, USA). Pearson $\chi^{2}$ tests and independent-sample $t$-tests were used to compare the independent variables versus dependent variables. The hypothesis about the equality of probability distribution was checked against the Mann-Whitney-Wilcoxon $U$ nonparametric criterion, and the corresponding $95 \% \mathrm{Cls}$ were calculated. To evaluate the interrelations among the factors, the method of logistic regression was used; $p$-value $<0.05$ was considered to be significant for all tests.

\section{Results}

In summary, 800 (80\%) completed responses were received. $606(75.8 \%)$ questionnaires confirmed those eligible by inclusion criteria. 25 (4.1\%) questionnaires were excluded because of age over $65,50(8,3 \%)$ had been clinically diagnosed with some disease, $30(5 \%)$ were currently unemployed, 62 (10.2\%) did not wish to participate in a continuous study, and 27 (4.5\%) questionnaires were completed inappropriately. Table 1 shows the characteristics of participants in the total group and the subgroups according to the state of health. The average age of participants was 41.1 years, and $78.5 \%$ (476) were women. The majority of respondents had a university degree $-59.1 \%$ (358), and $34 \%$ (208) were married. Work experience was equal to more than 20 years $-38.8 \%$ (235), with working from 9 to 12 hours a day $-44.6 \%$ (270) and resting from 7 to 8 hours $-40.8 \%$ (247). The income was from 500 to 1000 Euros a month $-51.8 \%$ (314). The biggest part of the respondents were representatives of different kind of specialists $-39.4 \%$ (239) with mainly sedentary $-33.8 \%$ (205) or sedentary with frequent physical activity $-37.8 \%$ (229) job characteristics, and the prevalence of stress-related risk factors at work was from $3.6 \%$ (22) of travelling to $40.3 \%$ (244) of environmental conditions (Table 7). 


\begin{tabular}{|c|c|c|c|c|}
\hline & Total $(n=606)$ & Optimal $(n=547)$ & Suboptimal $(n=59)$ & $p$ \\
\hline Age, mean (SD) & 41.1 (13.1) & $41.3(13.2)$ & $38.8(11.8)$ & $0.198^{*}$ \\
\hline $\begin{array}{l}\text { Gender, } n(\%) \\
\text { Men } \\
\text { Women }\end{array}$ & $\begin{array}{l}130(21.5) \\
476(78.5)\end{array}$ & $\begin{array}{l}124(22.7) \\
423(77.3)\end{array}$ & $\begin{array}{l}6(10.2) \\
53(89.8)\end{array}$ & $0.026 * *$ \\
\hline $\begin{array}{l}\text { Marital status, } n(\%) \\
\quad \text { Prefer not to say } \\
\text { Married } \\
\text { Single } \\
\text { Divorced } \\
\text { Widow }\end{array}$ & \begin{tabular}{|l|}
$279(46)$ \\
$208(34.3)$ \\
$11.9(7.2)$ \\
$37(6.1)$ \\
$10(1.7)$ \\
\end{tabular} & $\begin{array}{l}250(45.7) \\
194(35.5) \\
11.5(63) \\
31(5.7) \\
9(1.6) \\
\end{array}$ & $\begin{array}{l}29(49.2) \\
14(23.7) \\
9(15.3) \\
6(10.2) \\
1(1.7) \\
\end{array}$ & $0.323 * *$ \\
\hline $\begin{array}{l}\text { Level of education, } n(\%) \\
\text { Primary education } \\
\text { Incomplete secondary education } \\
\text { Secondary } \\
\text { Higher (K12) } \\
\text { High (college level) } \\
\text { High (university level) } \\
\text { PhD }\end{array}$ & \begin{tabular}{|l}
$1(0.2)$ \\
$16(2.6)$ \\
$91(15)$ \\
$76(12.5)$ \\
$58(9.6)$ \\
$358(59.1)$ \\
$6(1)$ \\
\end{tabular} & \begin{tabular}{|l}
- \\
$16(2.9)$ \\
$82(15.0)$ \\
$68(12.4)$ \\
$55(10.1)$ \\
$321(58.7)$ \\
$5(0.9)$ \\
\end{tabular} & $\begin{array}{l}1(1.7) \\
- \\
9(15.3) \\
8(13.6) \\
3(5.1) \\
37(62.7) \\
1(1.7) \\
\end{array}$ & $0.553^{*}$ \\
\hline $\begin{array}{l}\text { Work experience, } n \% \\
\text { Less than } 1 \text { year } \\
2-5 \text { years } \\
6-10 \text { years } \\
11-20 \text { years } \\
\text { More than } 20 \text { years }\end{array}$ & \begin{tabular}{|l|}
$53(8.7)$ \\
$83(13.7)$ \\
$89(14.7)$ \\
$146(24.1)$ \\
$235(38.8)$ \\
\end{tabular} & \begin{tabular}{|l}
$45(8.2)$ \\
$73(13.3)$ \\
$85(15.5)$ \\
$130(23.8)$ \\
$214(39.1)$ \\
\end{tabular} & $\begin{array}{l}8(13.6) \\
10(16.9) \\
4(6.8) \\
16(27.1) \\
21(35.6) \\
\end{array}$ & $0.426^{*}$ \\
\hline $\begin{array}{l}\text { Income per month, net, Eur, } n(\%) \\
\text { Less than } 500 \\
500-1000 \\
1000-1500 \\
1500-2000 \\
2000-2500 \\
2500-3000 \\
\text { More than } 3000 \\
\text { No answer }\end{array}$ & \begin{tabular}{|l}
$157(25.9)$ \\
$314(51.8)$ \\
$76(12.5)$ \\
$35(5.8)$ \\
$4(0.7)$ \\
$5(0.9)$ \\
$3(0.5)$ \\
$12(2)$ \\
\end{tabular} & \begin{tabular}{|l}
$139(25.4)$ \\
$281(51.4)$ \\
$71(13)$ \\
$32(5.9)$ \\
$4(0.7)$ \\
$5(0.9)$ \\
$3(0.5)$ \\
$12(2.2)$ \\
\end{tabular} & $\begin{array}{l}18(30.5) \\
33(55.9) \\
5(8.5) \\
3(5.1) \\
- \\
- \\
- \\
- \\
\end{array}$ & $0.324^{*}$ \\
\hline $\begin{array}{l}\text { Working hours per day, } n \% \\
\text { Less than } 8 \\
9-12 \\
13-16 \\
\text { More than } 16 \\
\text { Various }\end{array}$ & \begin{tabular}{|l|}
$250(41.3)$ \\
$270(44.6)$ \\
$22(3.6)$ \\
$20(3.3)$ \\
$44(7.3)$ \\
\end{tabular} & $\begin{array}{l}225(41.1) \\
249(45.5) \\
16(2.9) \\
17(3.1) \\
40(7.3) \\
\end{array}$ & $\begin{array}{l}25(4.4) \\
21(35.6) \\
6(10.2) \\
3(5.1) \\
4(6.8) \\
\end{array}$ & $0.302^{*}$ \\
\hline $\begin{array}{l}\text { Resting hours per day, } n \% \\
\text { Less than } 6 \\
7-8 \\
9-10 \\
\text { More than } 10 \\
\text { Various }\end{array}$ & $\begin{array}{l}128(21.1) \\
247(40.8) \\
127(21) \\
85(14) \\
19(3.1)\end{array}$ & $\begin{array}{l}106(19.4) \\
227(41.5) \\
115(21) \\
81(14.8) \\
18(3.3)\end{array}$ & $\begin{array}{l}22(37.3) \\
20(33.9) \\
12(20.3) \\
4(6.8) \\
1(1.7)\end{array}$ & $0.016^{*}$ \\
\hline
\end{tabular}

* By Mann-Whitney U, ** by Pearson chi-square.

The mean SHSQ score result was 20.9 (SD 11.9), with a minimum 0 and maximum 85. Optimal (less than 35 points) health was found in $90.3 \%$ (547) of respondents, and study outcome - SHS - was determined in less than in $10 \%$ of workers $(9.7 \%$ (59) (Table 2).

\begin{tabular}{|l|l|l|}
\hline \multicolumn{3}{|l|}{ Table 2. Health status of respondents } \\
\hline Health status & Frequency & $\%$ \\
\hline Optimal & 547 & 90.3 \\
\hline Suboptimal & 59 & 9.7 \\
\hline
\end{tabular}

Significant differences between groups were noted in gender (SHS was more observed in women) and resting hours (Table 1).

Based on different domains of health assessment, it was observed that in total SHSQ-25 and SHS, a significantly worse state was determined in the area of fatigue and mental system. If compared, all domain values were higher in SHS (Table 3).

\begin{tabular}{|l|l|l|l|}
\hline \multicolumn{5}{|l|}{ Table 3. Domains of health status in study groups } \\
\hline $\begin{array}{l}\text { Health status } \\
\text { domain }\end{array}$ & $\begin{array}{l}\text { Total SHSQ, } \\
\text { mean (SD) } \\
(n=606)\end{array}$ & $\begin{array}{l}\text { SHS, mean (SD) } \\
(n=59)\end{array}$ & $p$ \\
\hline Fatigue & $9.54(5.54)$ & $19.39(5.25)$ & $<0.001$ \\
\hline $\begin{array}{l}\text { Cardiovascular } \\
\text { system }\end{array}$ & $1.24(1.60)$ & $3.68(2.36)$ & $<0.001$ \\
\hline Digestive system & $1.31(1.49)$ & $2.93(2.10)$ & $<0.001$ \\
\hline Immune system & $2.17(1.84)$ & $4.10(2.51)$ & $<0.001$ \\
\hline Mental status & $6.64(4.37)$ & $14.15(4.02)$ & $<0.001$ \\
\hline
\end{tabular}

Considering the perceived symptoms attributable to various body systems between the health state groups, almost all symptoms (except for those attributed to endocrine, respiratory, urinary-gynaecology, eye and haematology spheres) were significantly greater in SHS, with the biggest prevalence of cardiovascular, gastrointestinal and musculoskeletal symptoms, as well as allergy and frequent infections (Table 4). 


\begin{tabular}{|l|l|l|l|l|}
\hline \multicolumn{2}{|l|}{ Table 4. Prevalence of perceived symptoms of respondents attributable to various diseases } \\
\hline Symptoms, $n$ (\%) & Total $(n=606)$ & Optimal $(n=547)$ & Suboptimal $(n=59)$ & $p$ \\
\hline Cardiovascular disease & $81(13.4)$ & $67(12.2)$ & $14(23.7)$ & 0.014 \\
\hline Musculoskeletal disease & $74(12.2)$ & $62(11.3)$ & $12(20.3)$ & 0.045 \\
\hline Gastrointestinal disease & $53(8.7)$ & $40(7.3)$ & $13(22)$ & $<0.001$ \\
\hline Nervous system disease & $29(4.8)$ & $21(3.8)$ & $8(13.6)$ & 0.001 \\
\hline Endocrine system disease & $92(15.2)$ & $82(15)$ & $10(16.9)$ & 0.69 \\
\hline Respiratory system disease & $23(3.8)$ & $19(3.5)$ & $4(6.8)$ & 0.207 \\
\hline Skin disease & $35(5.8)$ & $27(4.9)$ & $8(13.6)$ & 0.007 \\
\hline Ear disease & $11(1.8)$ & $7(1.3)$ & $4(6.8)$ & 0.003 \\
\hline Urinary-gynaecological disease & $40(6.6)$ & $35(6.4)$ & $5(8.5)$ & 0.542 \\
\hline Eye disease & $36(5.9)$ & $30(5.5)$ & $6(10.2)$ & 0.148 \\
\hline Haematological disease & $17(2.6)$ & $16(2.9)$ & $1(1.7)$ & 0.587 \\
\hline Allergy & $49(8.1)$ & $40(7.3)$ & $9(15.3)$ & 0.034 \\
\hline Frequent infectious diseases & $36(5.9)$ & $24(4.4)$ & $12(20.3)$ & $<0.001$ \\
\hline
\end{tabular}

\begin{tabular}{|l|l|l|l|}
\hline Table 5. Pearson correlation of health state and distress parameters \\
\hline & Number of distress symptoms & Distress symptom intensity & Management of distress symptoms \\
\hline Health status & 0.500 & 0.585 & -0.105 \\
\hline Sig. (1-tailed) & $<0.001$ & $<0.001$ & 0.005 \\
\hline
\end{tabular}

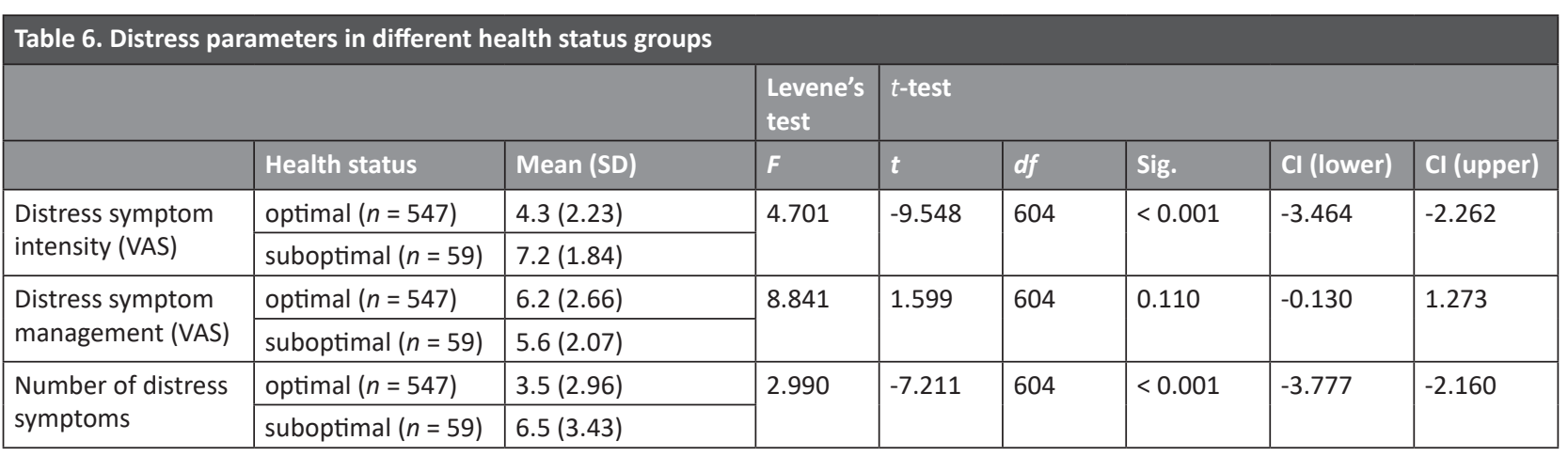

The evaluation of the second outcome - general distress - by GSDS of all respondents revealed that the respondents felt of 3.8 (SD 3.13) symptoms of distress, the overall intensity of which was 4.6 (SD 2.35) (VAS), and management of these equalled to 6.1 (SD 2.6) (VAS). The overall health state correlated with all distress parameters (Table 5).

When assessing the distress differences in different health status groups using the $t$-test, significantly more distress symptoms and bigger intensity were observed in SHS (Table 6).

During the present study, it was determined that despite health status, the most commonly experienced distress symptoms were fatigue, anxiety and sleep difficulties. All distress symptoms were significantly more prevalent in the SHS group (Figure 1).

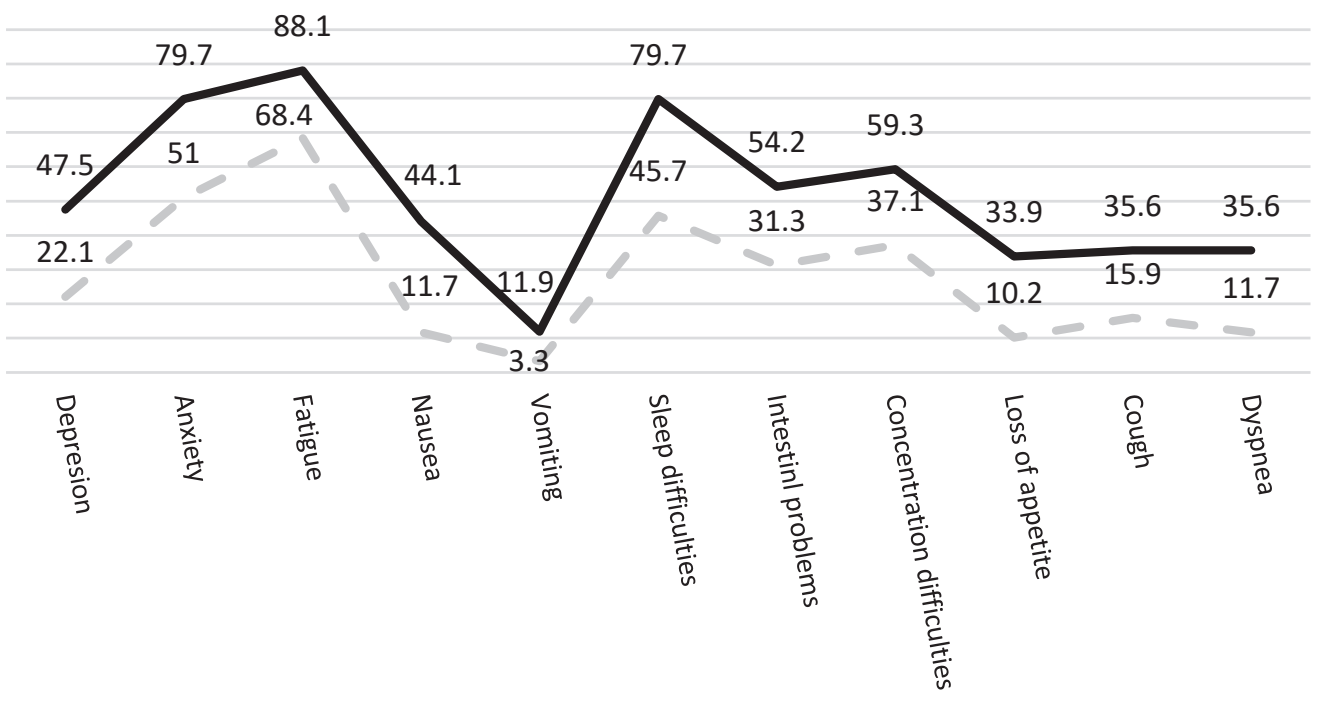

- Optimal health Suboptimal health

Figure 1. Distress symptom prevalence according to health state 


\begin{tabular}{|c|c|c|c|c|}
\hline & Total $(n=606)$ & Optimal $(n=547)$ & Suboptimal $(n=59)$ & $p$ \\
\hline $\begin{array}{l}\text { Profession, } n \text { (\%) } \\
\text { Leader } \\
\text { Specialist } \\
\text { Technicians and junior specialists } \\
\text { Officials } \\
\text { Service and sales } \\
\text { Qualified specialists in the field of land, forest, fisheries } \\
\text { Skilled workers and craftsmen } \\
\text { Machine operators } \\
\text { Unqualified workers } \\
\text { Armed forces } \\
\text { Unemployed according to specialty }\end{array}$ & \begin{tabular}{|l}
$14(2.3)$ \\
$239(39.4)$ \\
$10(1.7)$ \\
$31(5.1)$ \\
$56(9.2)$ \\
$3(0.5)$ \\
$20(3.3)$ \\
$4(0.7)$ \\
$8(1.3)$ \\
$2(0.3)$ \\
$219(36.1)$ \\
\end{tabular} & \begin{tabular}{|l}
$12(2.2)$ \\
$210(38.4)$ \\
$10(1.8)$ \\
$28(5.1)$ \\
$50(9.1)$ \\
$3(0.5)$ \\
$18(3.3)$ \\
$4(0.7)$ \\
$8(1.5)$ \\
$2(0.4)$ \\
$202(36.9)$ \\
\end{tabular} & \begin{tabular}{|l}
$\mid 2(3.4)$ \\
$29(49.2)$ \\
$0(0)$ \\
$3(5.1)$ \\
$6(10.2)$ \\
$0(0)$ \\
$2(3.4)$ \\
$0(0)$ \\
$0(0)$ \\
$0(0)$ \\
$17(28.8)$ \\
\end{tabular} & 0.829 \\
\hline $\begin{array}{l}\text { Character of the work, } n(\%) \\
\text { Mainly sedentary } \\
\text { Sedentary with frequent physical activity } \\
\text { Mainly physical } \\
\text { Physical with frequent intense activity }\end{array}$ & \begin{tabular}{|l|}
$205(33.8)$ \\
$229(37.8)$ \\
$139(22.9)$ \\
$20(3.3)$ \\
\end{tabular} & \begin{tabular}{|l|}
$184(33.6)$ \\
$210(38.4)$ \\
$124(22.7)$ \\
$16(2.9)$ \\
\end{tabular} & $\begin{array}{l}21(35.6) \\
19(32.2) \\
15(25.4) \\
4(6.8) \\
\end{array}$ & 0.334 \\
\hline $\begin{array}{l}\text { Stress-related factors at work, } n(\%) \\
\text { Competition } \\
\text { Deadline } \\
\text { Environmental conditions } \\
\text { Potential to growth in a professional field } \\
\text { Facing danger } \\
\text { Life threatening } \\
\text { Risk perceived in another person's life } \\
\text { Meetings with public } \\
\text { Physical requirements } \\
\text { Travelling } \\
\text { Work in publics }\end{array}$ & $\begin{array}{l}141(23.3) \\
223(36.8) \\
244(40.3) \\
61(10.1) \\
87(14.4) \\
33(5.4) \\
86(14.2) \\
72(11.9) \\
56(9.2) \\
22(3.6) \\
114(18.8)\end{array}$ & $\begin{array}{l}123(22.5) \\
198(36.2) \\
218(39.9) \\
49(9.0) \\
80(14.6) \\
27(4.9) \\
71(13) \\
63(11.5) \\
49(9) \\
16(3.3) \\
97(17.7)\end{array}$ & \begin{tabular}{|ll}
18 & $(30.5)$ \\
25 & $(42.4)$ \\
26 & $(44.1)$ \\
12 & $(20.3)$ \\
7 & $(11.9)$ \\
6 & $(10.2)$ \\
15 & $(25.4)$ \\
9 & $(15.3)$ \\
7 & $(11.9)$ \\
4 & $(6.8)$ \\
17 & $(28.8)$ \\
\end{tabular} & \begin{tabular}{|l}
0.166 \\
0.35 \\
0.531 \\
0.006 \\
0.566 \\
0.092 \\
0.009 \\
0.399 \\
0.464 \\
0.173 \\
0.039
\end{tabular} \\
\hline
\end{tabular}

$p$ - by Pearson chi-square.

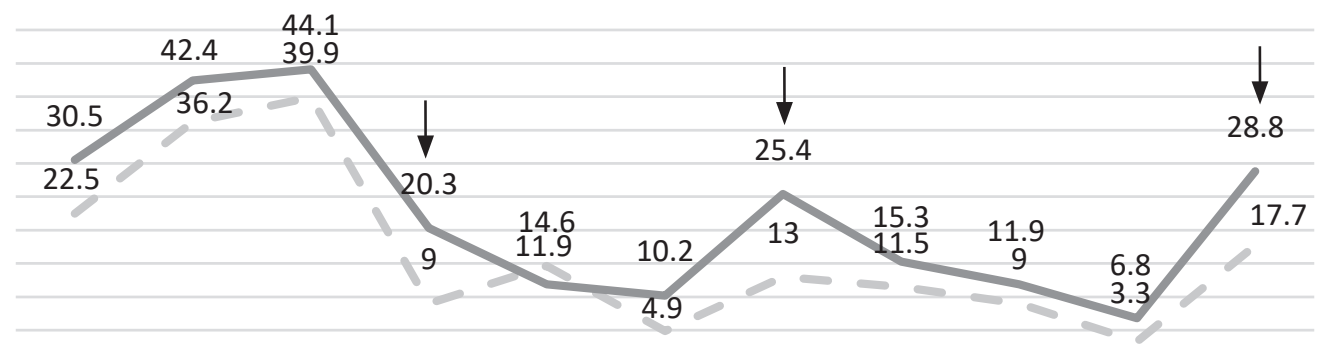

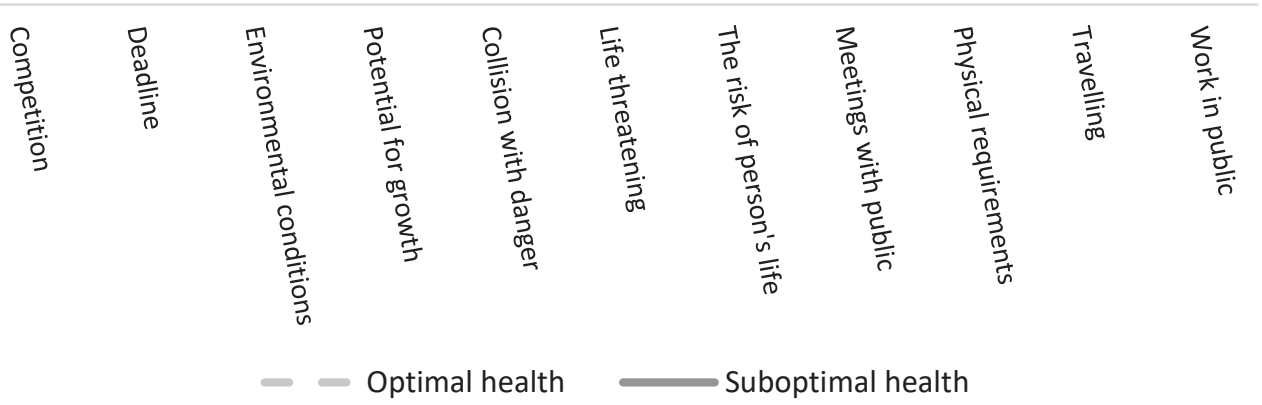

Figure 2. Prevalence of work-related stress factors according to health state

The study showed no significant role of socio-demographic characteristics such as age, education, marital status, work experience, income or working hours in the SHS group. A significant factor was only resting hours $(p=0.016)$. Nevertheless, shorter work and less income was found in SHS (Table 1).

We found no significant effect of profession and characteristic of work on SHS; however, job-related stress-risk factors such as potential to grow in a professional field, risk perceived in another person's life and work in public have significant influence on SHS (Table 7).
Almost all stress-related work risk factors (except for facing danger) were more prevalent in the SHS group (Figure 2).

When evaluating the overall health state, there was a significant correlation was identified between the overall health state and most of the work-related risk factors (Table 8). Better work experience, better income and resting time have a positive influence on health; intense competition, deadlines, environmental conditions, professional growth potential, risk perceived in another person's life, meetings with public, physical requirements and work in public have a negative influence on health. 


\begin{tabular}{|l|l|l|l|l|l|}
\hline \multicolumn{2}{|l}{ Table 8. Pearson correlation of work-related factors with health state } \\
\hline Factor & Health state & $\boldsymbol{p}$ & Factor & Health state & $\boldsymbol{p}$ \\
\hline Work experience & -0.101 & 0.007 & potential for professional growth & 0.181 & $<0.001$ \\
\hline Income & -0.085 & 0.018 & risk in another person's life & 0.127 & 0.001 \\
\hline Resting hours & -0.139 & $<0.001$ & meetings with public & 0.091 & 0.013 \\
\hline Competition & 0.110 & 0.03 & physical requirements & 0.097 & 0.009 \\
\hline Deadlines & 0.116 & 0.002 & work in public & 0.138 & $<0.001$ \\
\hline Environment & 0.092 & 0.012 & & & \\
\hline
\end{tabular}

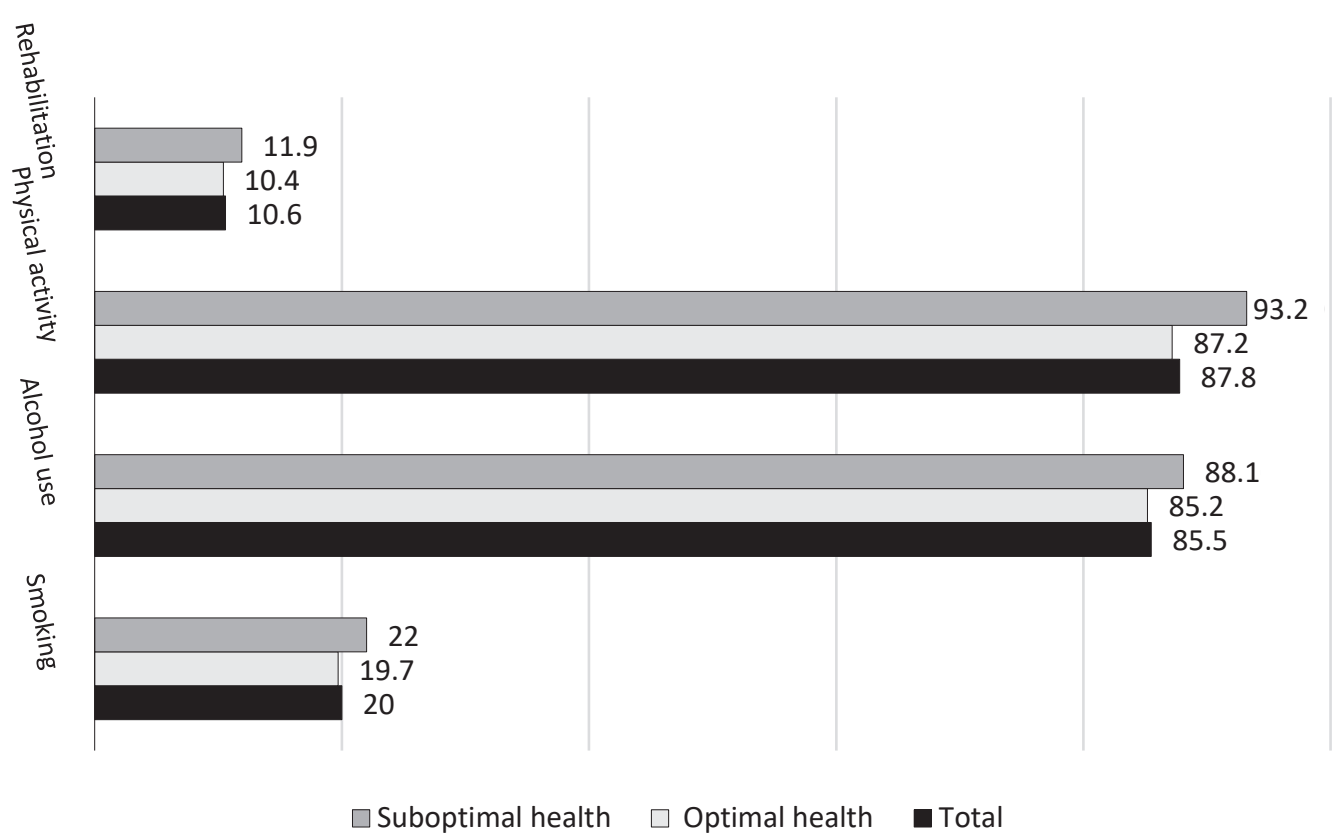

Figure 3. Prevalence of behavioural factors according health state [\%]

There was no significant difference in health state groups according to behavioural risk factors. The results showed the prevalence of smoking, which in the total group was $20 \%$ (121) (every day smoking $-8.1 \%(49)$ and not different in SHS - 22\% (13)) (every day smoking $-8.5 \%(5)(p=0.652)$; alcohol use in total was $85.5 \%$ (518) (every day - $0.7 \%(4))$ compared with $88.1 \%$ (52) (every day $-3.4 \%(2))$ in SHS ( $p=0.859)$; physical activity in total was $87.8 \%(542)$ (every day $-11.6 \%(70))$, and in the SHS group, it was $93.2 \%(55)$ (every day $-15.3 \%(9))(p=0.989)$, and the application of rehabilitation procedures in total was $10.6 \%$ (64), and in SHS, it was $11.9 \%$ (7) $(p=0.732)$ (Figure 3).

\section{Discussion}

The aim of this study was to evaluate SHS prevalence and general distress, as well as the relationship between health status and distress, including job-related factors, so as to obtain a more complete profile of the well-being of workers and to identify more effective intervention measures. The clinical study has demonstrated that $90 \%$ (547) of respondents had an optimal health level and only $9.7 \%$ (59) had SHS. The study participants felt nearly four symptoms of distress on average with 5 (VAS) intensity and 6 (VAS) management points. The study has shown a reliable connection of overall health status with all parameters of distress, and SHS with a number of distress symptoms and their intensity.

The main domains of health status in our study were fatigue and mental status. SHS was related with cardiovascular, digestive, musculoskeletal symptoms, frequent infections and allergy. SHS was more prevalent in woman and did not depend on age, education (college) and marital status, nor profession, character of work, income, experience, some job stress-related factors, as well as behavioural habits. Work-related stress risk factors, such as professional potential to grow, risk in another person's life and work in public, have a significant influence on SHS, as well as on resting hours.

The results of the present study differ from the results in China or the UAE, where the prevalence rate of SHS was $55.9 \%$ (6234) [13] and 52.5\% (265) [20]. This reason could be the different sample size and the characteristics or different working/ /studying conditions or different methodology (using median score or $>35$ points). In European study samples, the health self-rating is better: $8.7 \%$ of the participants rated their health as excellent, $35.8 \%$ rated as very good, $45.6 \%$ rated as good, $8.9 \%$ rated as fair, and $1 \%$ as poor [21]. The present study found that the mean SHSQ score was 20.9, which was lower than 33.3 in other trials [20]. In a similar age group with less women, the authors found the mean SHS score among the SHS group was $55.73 \pm 9.58$ (SHS score $>44$ and $35.02 \pm 6.51$ among the control group (SHS < 44)), respectively [2]. The difference could be explained as follows: the rapid economic progress across China and employees becoming more exposed to stressful situations, such as excessive workload, competition and perceived loneliness [2]. In another trial, the SHS scores of White-Collar Workers ( $n=1497)$, Blue-Collar Workers $(n=507)$ and College Students ( $n=345$ ) were 59.81, 45.28, and 38.96, respectively [16]. Our results are comparable to Youxin Wang's (China) suboptimal health cohort study (COACS), where the prevalence of SHS was 9\% (389), using an SHS score of 35 as a threshold, where women showed a significantly higher prevalence of SHS. Risk factors for chronic diseases, such as socio-economic status, marital status, higher education, physical activity, salt intake, blood pressure and triglycerides, differed significantly between subjects of SHS (SHS score $\geq 35$ ) and those of ideal health (SHS score $<35)[22]$. 
The reason for the different results of self-perceived measures could be the different feelings about subjective health (general health, mental health, one's life stress). People rate their health in relative terms comparing themselves with others in the community and their expectations [23]. In a 2016 trial (24 159 participants), SHS was found in $46 \%$ of respondents, and compared with to participants with a healthy lifestyle, subjects with a 'poor' lifestyle were at a 43 times higher risk of developing SHS (OR 42.825) [24]. Other researchers also found that health status was significantly positively correlated with lifestyle $[11,13]$. Our trial did not show a significant relation with the behavioural habits (we did not take into account nutritional habits), similarly to the UEA (no association with physical activity and smoking) [20].

The present study identified that overall health status depends on job-related risk factors: professional potential to grow, rest, work in public, risk in another person's life, deadlines, competition, work experience, physical requirements, environment, meetings with public and income. According to CareerCast, career and money-related issues are two of the leading and most consistent year-to-year causes of stress [17]. Shorter work experience (less than 1 year $8.2 \%$ vs $13.6 \%$ ), longer working hours (13-16 hours in $2.9 \%$ vs $10.2 \%$ ) and smaller income was found in SHS. Social determinants can strengthen or undermine the health of individuals and communities. People from poorer social or economic circumstances are at greater risk of poor health than people who are more advantaged [7]. In students, factors associated with SHS were age (younger), study year (first years) and nationality [21]. The present study found that age (Pearson correlation $0.142(p<0.001))$ and work experience were associated with the overall health state, but not the SHS.

The present research showed the association between distress and overall and health state SHS. Fatigue, anxiety and sleep disturbances were mostly prevalent. According to other studies, the most frequent symptom of stress was fatigue (90.5\%), as well as nervousness (81\%) and poor sleep (42.9\%), and the correlation between the score for SHS (53.67) and that for experienced stress (72.67) was statistically significant [16]. Other studies have already identified stress as a key factor contributing to poor public health [25]. Chronic overwhelming stress leads to exhaustion, and this state of exhaustion is marked by energy depletion and tissue degeneration [26]. In the general population, the major risk factors for SHS included poor stress management, poor self-actualisation, inactivity and poor interpersonal relationships [24]. The serum cortisol level was found to be much higher among the SHS high-score group than that of the low SHS score group. SHS is associated with cardiovascular risk factors and contributes to the development of cardiovascular disease. SHS should be recognised in the health care system, especially in primary care [11]. Family doctors must pay attention to the number of patients' complaints and their intensity for further studies concerning SHS or the possible presence of diseases. Distress symptoms, especially fatigue, anxiety and sleep disturbances, must be addressed by effective measures.

In general, the health of a majority of Klaipeda's workers is optimal, but distress is prevalent and partly dependent upon specific work stress factors. Pursuant to the findings of the present study, it is necessary to pay attention to the prevention and lowering of the number of stress symptoms, stress intensity and growing stress management strategies, as well as to evaluate workplace safety regarding stress-related risk factors, as they are associated with health status. The guidelines for employers must include improvement of physical working conditions, regulation of workload, human effort assessment, healthy working atmosphere, psychological assistance for workers dealing with the public and taking responsibility for another person's life, as well as a fair and sufficient salary.

The concepts of health and disease are crucial in defining the aim and the limits of modern medicine. Accordingly, it is important to understand them, as well as their relationship, in order to find the best tool to assess the health state and be able to take preventative measures [27].

\section{Limitations of the study}

The limitation of the study could be unequal distribution of respondents by profession, limited number of job-related factors, low prevalence of SHS.

It would be necessary to perform a much larger-scale study in order to compare the results with other SHS trials and to be able to compare the SHS of all country population results, as well as with those of other European workers with similar results of job-related factors. Further studies could be supplemented with questions about possible preventative measures to lower work-related stress and to increase general health. There is a need for research to compare the different types of work-stress prevention measures to determine their impact on distress and health change. Prevention, prediction and personalisation of medicine are the aims of any integrated preventive treatment plan.

\section{Conclusions}

1. SHS prevalence in the study population was $9.7 \%$. The main health impairment domains are fatigue and mental disturbances.

2. SHS depends on distress symptom number and intensity. The main distress symptoms for SHS are fatigue, anxiety and sleep disturbances.

3. Health status depends on job-related risk factors: professional potential to produce, rest, work in public, risk in another person's life, deadlines, competition, work experience, physical requirements, environment, meetings with public and income. The professional potential to grow, the risk in another person's life and work in public have a significant influence on SHS.

Source of funding: This work was funded from the authors' own resources.

Conflicts of interest: The authors declare no conflicts of interest.

\section{References}

1. Health. Merriam-Webster Dictionary. 2012 [cited 19.08.2018]. Available from URL: http://www.merriam-webster.com/dictionary/ health.

2. Wang W, Yan YX. Suboptimal health: a new health dimension for translational medicine. Clin Transl Med 2012; 1(28): 5-6.

3. Wang W, Russell A, Yan Y. Traditional Chinese medicine and new concepts of predictive, preventive and personalized medicine in diagnosis and treatment of suboptimal health. EPMA J 2014; 5 [cited 19.08.2018]. Available from URL: https://www.researchgate. net/publication/260167397_Traditional_Chinese_medicine_and_new_concepts_of_predictive_preventive_and_personalized_medicine_in_diagnosis_and_treatment_of_suboptimal_health.

4. Wang Y. Subhealth: a new concept of health for the 21st century. Nanchang: Jiangxi Science and Technology Press; 2002.

5. Roser M, Ritchie H. Burden of disease [cited 1.09.2018]. Available from URL: https://ourworldindata.org/burden-of-disease.

6. WHO. World health statistics 2017 [cited 1.09.2018]. Available from URL: http://apps.who.int/iris/bitstream/hand le/10665/255336/9789241565486-eng.pdf;jsessionid = 855C4CD8A8CD5F04643E8F4984A5CF1B sequence $=.1$. 
7. Australia's health 2016 [cited 1.09.2018]. Available from URL: https://www.aihw.gov.au/reports/australias-health/australiashealth-2016/contents/chapter-4-determinants-of-health.

8. Stansfield S, Head J, Marmot M. Work related factors and ill health. The Whitehall II Study. 2000 [cited 1.09.2018]. Available from URL: http://www.hse.gov.uk/research/crr_pdf/2000/crr00266.pdf

9. Mozaffarian D, Hao T, Rimm EB, et al. Changes in diet and lifestyle and long-term weight gain in women and men. N Engl J Med 2011; 364: 2392-2404.

10. Sun XM, Wei M, Zhu CY, et al. An investigation of suboptimal health status in Guangdong: a cross section study. Shandong Med J 2008; 48: 59-60.

11. Yan YX, Dong J, Liu YQ, et al. Association of suboptimal health status and cardiovascular risk factors in urban Chinese workers. J Urban Health 2012; 89: 329-338.

12. Qiang L, Xiumin Z, Jinghua L, et al. Investigation and analysis of suboptimal health status influencing factors in community inhabitants of Shenyang city. Med Soc 2010; 2: 33-35.

13. Bi J, Huang $Y$, Xiao $Y$, et al. Association of lifestyle factors and suboptimal health status: a cross-sectional study of Chinese students. BMJ Open 2014; 4(6): e005156, doi: doi:10.1136/bmjopen-2014-005156.

14. Fact Sheet: Health disparities and stress. American Psychological Association [cited 1.09.2018]. Available from URL: http://www.apa. $\mathrm{org} /$ topics/health-disparities/fact-sheet-stress.aspx.

15. Siu OL, Spector PE, Cooper CL, et al. Work stress, self-efficacy, Chinese work values, and work well-being in HongKong and Beijing. Int J Stress Man 2005; 12: 274-288.

16. Yan YX, Liu IQ, Li M, et al. Development and evaluation of a questionnaire for measuring suboptimal health status in urban Chinese. J Epidemiol 2009; 19(6): 333-341.

17. The most stressful jobs of 2018 [cited 15.08.2018]. Available from URL: https://www.careercast.com/jobs-rated/2018-most-stressfuljobs.

18. McHorney CA. Health status assessment methods for adults: past accomplishments and future challenges. Ann Rev Pub Health 1999; 20(1): 309-335.

19. Badger TA, Segrin C, Meek P. Development and validation of an instrument for rapidly assessing symptoms: the General Symptom Distress Scale. J Pain Symp Man 2011; 41(3): 535-548.

20. Al-Hemyari SS, Jairoun AA, Abdulla N. Assessment of suboptimal health status and their associated risks in university students: a cross-sectional study, UAE. J Pharm Res 2017; 11(8) [cited 1.09.2018]. Available from URL: http://jprsolutions.info/files/final-file59c3d5e731c666.53798165.pdf.

21. Mikolajczyk RT, Brzoska P, Maier C, et al. Factors associated with self-rated health. status in university students: a cross-sectional study in three European countries. BMC Public Health 2008; 8: 215, doi: 10.1186/1471-2458-8-215.

22. Wang Y, Ge S, Yan Y, et al. China suboptimal health cohort study: rationale, design and baseline characteristics. J Trans Med 2016; 14: 291, doi: doi.org/10.1186/s12967-016-1046-y.

23. Idler EL, Benyamini Y. Self-rated health and mortality: a review of twenty-seven community studies. J Health Soc Beh 1997; 38(1): 21-37.

24. Chen JY, Yang LB, Jiang PP, et al. Associations between health-promoting lifestyle and suboptimal health status in Guangdong: a cross sectional study. Nan Fang Yi Ke Da Xue Xue Bao 2016; 36(4): 538-543.

25. Augusto Landa JM, López-Zafra E, Berrios Martos MP, et al. The relationship between emotional intelligence, occupational stress and health in nurses: a questionnaire survey. Int J Nurs Stud 2008; 45: 888-901.

26. Braun CA, Anderson CM. Pathophysiology: functional alterations in human health. Philadelphia: Lippincott Williams \& Wilkins; 2006.

27. Hofmann B. Simplified models of the relationship between health and disease. Theor Med Bioeth 2005; 26: 355-377, doi: doi:10.1007/ s11017-005-7914-8.

Tables: 8

Figures: 3

References: 27

Received: 8.09.2018

Reviewed: 10.09 .2018

Accepted: 4.12 .2018

Address for correspondence:

Lina Gedrimè, MSc

Klaipeda University

Herkaus Manto g. 84

LT-92294 Klaipèda

Lithuania

Tel.: +37068620439

E-mail: linagedrimaite@gmail.com 